\title{
Exponential Manipulative Chips In Learning Integral Exponent
}

\author{
Grace P. Guliman, Emybel M. Alegre,PhD \\ DOI: 10.29322/IJSRP.11.10.2021.p11826 \\ http://dx.doi.org/10.29322/IJSRP.11.10.2021.p11826
}

\begin{abstract}
This study attempted to determine the student's performance level in learning integral exponent of grade 8 students. The descriptive research method was used in this study where a total population of 70 respondents was obtained using cluster random sampling. The research instrument was validated and tested using Cronbach's Alpha. The descriptive analysis, mean, and paired t-test were utilized for statistical analysis.

The main purpose of the study was to determine if there is a significant difference between the student's performance in the pre-test and post-test assessment in learning integral exponents with the aid of exponential manipulative chips. The mean and paired t-test was used as the statistical treatment to determine if there is a significant difference in their performance in the pre-test and post-test.

The gathered data undergo statistical analysis with the use of appropriate statistical tools and arrived with result that there is a significant difference between the student's performance in learning integral exponent in the pre-test and post-test, with a pvalue of 0.007 less than the 0.05 alpha. Students also find the use of manipulatives very useful having an overall rating mean on their perception of 4.4 interpreted as very useful, thus an exponential manipulative chip is an effective instructional tool in learning integral exponents.
\end{abstract}

Index Terms- Integral exponent, mathematics' performance, Manipulative chip

\section{INTRODUCTION}

$\mathrm{M}$ athematics plays an important role in human life. It gives a foundation that is used in real-life situations for daily living. The concept of mathematics has been introduced as an important component of formal education at a very early age. It was then offered as one of the subjects in the first grade of the learner as they entered formal education. Mathematics was more abstract that makes students have difficulties in learning mathematical concepts. But our educational curriculum cannot disregard the use and importance of learning mathematics in real life. It is then a challenge for educators to developed varied instructional materials that helped to aid the difficulties of students in learning the concepts of mathematics. Learning Mathematics is very crucial especially during secondary years, it serves as the child's foundation in preparation for college. Students during this period must develop a conceptual understanding of the mathematical concepts to build their foundation. Integral exponent was an important mathematical concept introduced in secondary education. It includes the application of rules and laws in simplifying algebraic expressions. Most secondary students perceived exponent as challenging and complicated concepts that are unnecessary and have no connection with everyday life, (Senay 2002). This was originally due to a lack of exponential number sense and difficulty to have a better conceptual understanding of the abstract concept of the rules and laws of exponents. Consequently, for the students to cope with the subject it takes a lot of motivation to increase students' interest in mathematics specifically in learning integral exponent. It is, therefore, one way to help overcome this learning problem is to use instructional materials that can be interesting and stimulating for the students in the classroom.

Accordingly, the use of manipulative as instructional materials is one way for the students to cope up with their difficulties in developing conceptual understanding of the abstract ideas in mathematics, (Domino, 2010). The concrete nature of manipulative means for the students to exert physical action which made them be the active participant of learning, with this the students were engaged in learning, (Cooper,2012). As the students were actively engaged in the learning process, the more they learn and were motivated on the subject. Thus, the use of manipulative in mathematics helps them in understanding the concepts than relying too much on worksheets and opportunities to control the learning environment, and it helps to cater to the different learning styles of the students (Mc Neil \& Jarvin 2007). Manipulative also provides students concrete experiences in learning the concepts, which will result in the higher cognitive development of the child. This helped students to discuss mathematical concepts and to verbalize their mathematical thinking and ideas, (Ojose, 2008).

The researchers, therefore, decided to undertake this research to determine the effect of using exponential chips as manipulatives in learning integral exponent for the reason that it may help the educators in delivering their lessons effectively.

\section{THEORETICAL FRAMEWORK}

This study entitled "Exponential Manipulative Chips in Learning Integral Exponent" was chosen by the researcher to determine the effect of using manipulative such as exponential chips in learning integral exponent.

This study was anchored on the theory of experiential learning introduced by David A. Kolb. The theory of experiential learning revolves around the idea that learning is enhanced when students acquire knowledge through active processes that engage them (Hartshorn and Boren, 1990). Experiential learning is a method of educating through first-hand experience. Kolb's 
experiential learning theory is a holistic perspective that combines experience, perception, cognition, and behavior.

In this theory, Kolb believes that "learning is the process whereby knowledge is created through the transformation of experience" (Kolb, 1984, p.38). He also states that learning involves acquiring abstract concepts that can be applied flexibly in a range of situations. In Kolb's theory, the impulse for the development of new concepts is provided by new experiences, So, effective learning is seen when a person progresses through a cycle of four stages: (1) having a complete concrete experience followed by (2) observation of and reflection on that experience which leads to (3) the formation of abstract concepts (analysis) and generalizations (conclusion) which are then (4) used to test a hypothesis in future situations, resulting in new experiences. Manipulative can be key in providing effective, active, engaging lessons in the teaching of mathematics that will allow the students to experience a new way of meaningful learning. Thus, in this study, the students will experience a new way of teaching for them to have interactive and meaningful learning.

The concept of manipulative also involves Piaget's theory on the stages of cognitive development (1977). Piaget believed that students progress through four stages of development beginning with the sensory-motor stage in infancy, the preoperational stage in early childhood. Piaget's theory as it relates to mathematics instruction was summarized by Ojose (2008) he describes how students need concrete experiences to "lay the foundation for more advanced mathematical thinking" as they move from the concrete operational stage to the formal operations stage (p.28). In addition to helping students advance to higher levels of cognitive development, manipulative can help students who already possess the ability to think abstractly. Modeling a mathematical concept with manipulative leads students to think about mathematics differently and attain a higher level of understanding (Cooper, 2012). Teaching with manipulative incorporates a multi-representational approach to mathematics which meets the needs of students with a variety of learning styles (McNeil \& Jarvin, 2007).

\section{CONCEPTUAL FRAMEWORK:}

This study rested on the concept that using exponential chips as a manipulative affects learning integral exponent in grade eight students. It is important for teachers nowadays to have a variety of teaching strategies and methods to catch the attention of the learners. One of the tools that can be used is manipulative.

In this study, the independent variable is the performance of the respondents in integral exponent before introducing exponential chips as Manipulative (pre-test) and the level of perception of the respondents in exponential chips as Manipulative, and the dependent variable is the performance of the respondents in integral exponent after introducing exponential chips as Manipulative (post-test). It shows how the use of exponential chips as manipulative affects the learning performance of the students about integral exponent. By this variable, the researchers will be able to determine the effect of exponential manipulative chips in learning integral exponent.

\section{This schematic diagram that follows illustrates the interplay of the variance of this study.
Independent Variable
Dependent Variable
Output

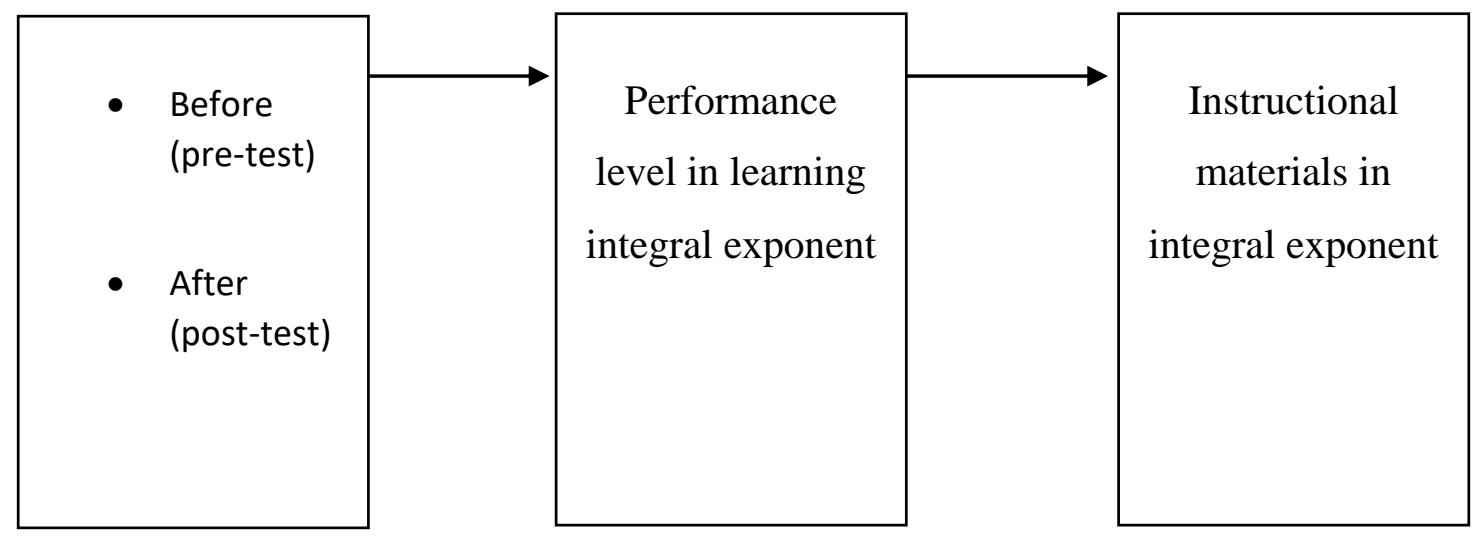

Figure 1: The Schematic Diagram showing the independent and dependent variables.

\section{RESEARCH METHODOLOGY}

The descriptive method was used as the research design in this study to achieve the objectives of the study. The descriptive method was used as the survey technique, which was the most appropriate method to be used in determining the student's perception of the use of exponential manipulative chips in learning integral exponent. It is also used to describe the performance of the respondents in the pre-test and post-test in learning integral exponent.
This study was conducted in Noli National High School at Bayugan City, province of Agusan Del Sur, Philippines. It was just one ride away from Ampayon, Butuan City and it takes 30-45 minutes ride of a bus or van as a means of transportation to arrive at said school. It was located in the Barangay of Noli alongside the National highway beside Noli Central Elementary School. Figure 2 shows the map of Noli National High School.

The main instrument that was used in this study was the self-structured questionnaire designed based on the research question. The questionnaire was composed of two questions. The first one was the pre-test and post-test assessment in learning 
integral exponent, with and without the intervention of exponential manipulative chips. The second was on the student's perception of the use of exponential manipulative chips in learning integral exponent. The respondents were required to answer the given questions of their own choice.

The self-made questionnaire by the researcher was submitted to experts for validation purposes. The researcher then conducted a pilot test of their instrument about 35 grade 8 respondents in Taligaman National High School. The result was subjected to a reliability test index and 0.83 Cronbach's Alpha was obtained.

The researchers sent a letter to ask permission from the principal of the selected school to allow them to conduct pre-test, post-test in learning integral exponent of grade 8 students, and the distribution of survey questionnaire on perception to the respondents. After given permission, four days of pre-test and post-test assessment were conducted. Before the conduct of the post-test, the researcher administered a discussion on how exponential manipulative chips work in learning integral exponent, and then the post-test followed to assess students. After the post-test, the researcher distributed the survey questionnaires to the respondents to be answered with an allotted time to finish. Before answering, a brief orientation is administered for the instruction and clarification of the respondents about the questionnaire to be answered. The researchers retrieved the questionnaire right after the respondents answered all the items or the question. The data was obtained, scored, tallied, and tabulated for statistical analysis.

The gathering is quantified according to its level with descriptive rating.

Students Perception on the use of Exponential Manipulative Chips in Learning Integral Exponent

\begin{tabular}{|c|c|}
\hline Scale & Range \\
\hline \multicolumn{2}{|c|}{ Verbal Description } \\
\hline 4 & $1.00-2.00$ \\
\hline \multicolumn{2}{|c|}{ Strongly Disagree } \\
\hline 3 & $2.01-3.00$ \\
\hline & \\
\hline 2 & $3.01-4.00$ \\
\hline & \\
\hline 1 & $4.01-5.00$ \\
\hline
\end{tabular}

Students Perception on the use of Exponential Manipulative Chips in Learning Integral Exponent's Verbal Interpretation of Overall Rating

Table 2. The performance level of grade 8 students in pre-test and post-test

\begin{tabular}{cl} 
Ranges & \multicolumn{1}{c}{ Verbal Interpretation } \\
$1.00-1.80$ & Not Useful \\
$1.81-2.60$ & Slightly Useful \\
$2.61-3.40$ & Moderately Useful \\
& \\
$3.41-4.20$ & Useful \\
$4.20-5.00$ & Very Useful
\end{tabular}

Performance Level of Grade 8 Students in Pre-test and Posttest Based on DepEd Rating System

Ranges
Interpretation

Below 75

meet expectation
$75-79$
$80-84$
$85-89$
$90-100$
Outstanding

\author{
Verbal
Did not \\ Verbal
Did not \\ Fairly Satisfactory \\ Satisfactory \\ Very Satisfactory
}

The following statistical treatment was used in the study.

Cronbach Alpha. This tool was utilized to determine the level of reliability of the questionnaire.

Mean. It was used to describe the responses of the participants with regards to Exponential Manipulative Chips.

Paired t-test. This statistic was employed to determine the difference between the Pre-test and Post-test performance of the students.

Descriptive analysis. This tool was used to determine the perception of the students on Exponential Chips as manipulative in learning integral exponent in the classroom.

\section{PRESENTATION, ANALYSIS, AND INTERPRETATION OF DATA}

Problem 1. What is the performance level of the respondents in terms of pre-test and post-test in learning integral exponent?

Table 2 shows the performance of the Grade 8 students in the pretest and post-test.

\begin{tabular}{llll}
\hline & & $\begin{array}{l}\text { Mean Rating } \\
(\boldsymbol{\%}) *\end{array}$ & Verbal Description \\
\hline \hline Section 1 & Pre-test & 49.13 & Did not meet expectations \\
& Post-test & 84.40 & Very Satisfactory \\
Section 2 & Pre-test & 30.33 & Did Not Meet Expectations \\
& Post-test & 78.07 & Fairly Satisfactory \\
Overall & Pre-test & 39.73 & Did Not Meet Expectations \\
\hline
\end{tabular}




\section{Post-test $\quad 81.20 \quad$ Satisfactory}

*below 75 Did Not Meet Expectations; 75-79 Fairly Satisfactory; 80-84 Satisfactory; 85-89 Very Satisfactory; 90-100 Outstanding

Based on the DepEd rating system, the performance of the students in the pre-test did not meet the expectations as reflected in their below $75 \%$ means. However, the students' post-test performance reached the satisfactory rating with section 1 having an $84.40 \%$ rating (Very satisfactory) and section 2 having a $78.07 \%$ rating (Fairly Satisfactory). Overall, the two sections got an $81.20 \%$ rating with a Satisfactory performance. Boggan, Harper, and Whitmire (2010), "manipulatives help students learn by allowing them to move from concrete experiences to abstract reasoning"(p.4). Manipulatives are an effective teaching tool because teachers can use them to teach students how to bridge the gap between concrete and abstract reasoning.

Problem 2. Is there any significant difference in the performance level of the respondents between the pre-test and post-test?

Table 3 shows the result of a Paired samples t-test on SPSS tested at a 0.05 level of significance.

Table 3. Comparison of means between pre-test and post-test scores of grade 8 students

\begin{tabular}{lllll}
\hline & & Mean & P-Value* & Remark \\
\hline \hline Section 1 & Pre-test & 7.37 & 0.002 & Significant \\
& Post-test & 12.66 & & \\
Section 2 & Pre-test & 4.55 & 0.001 & Significant \\
& Post-test & 11.71 & & Significant \\
Overall & Pre-test & 5.96 & 0.007 & \\
& Post-test & 12.18 & & \\
\hline
\end{tabular}

*tested at 0.05 level of significance using Paired Sample T-Test

The results show that there is a significant difference in the scores of Section 1 and Section 2 students in pre-test and posttest scores with a p-value of 0.002 and 0.001 , respectively. Overall, there is a significant difference in the pre-test and posttest scores of Grade 8 students with a p-value of 0.007 , having a higher mean in the post-test compared to the pre-test.

Thus, it can be concluded that the use of exponential chips is effective in improving the performance of the students in simplifying expressions with integral exponent. Swan \& Marshall et. Al., (2010) majority of the findings on researches mathematics resulting in better achievement and conceptual understanding than of the traditional teaching technique.

Problem 3. What is the perception of the respondents in using exponential manipulative chips in learning integral exponent?

Table 4 shows the perception of the grade 8 students in the use of exponential chips as manipulative in learning integral exponent.

Table 4. Perception on the exponential manipulative chips of grade 8 students

\begin{tabular}{rlll}
\hline Indicators & Mean Rating* & Interpretation \\
\hline \hline 1. & $\begin{array}{l}\text { Exponential manipulative chips capture my interest in } \\
\text { learning integral exponents. }\end{array}$ & Strongly Agree \\
2. & $\begin{array}{l}\text { The use of exponential chips as conceptual } \\
\text { understanding in learning integral exponent. }\end{array}$ & Strongly Agree \\
3. $\begin{array}{l}\text { Using exponential chips help my teacher to deliver the } \\
\text { lesson effectively. }\end{array}$ & Strongly Agree \\
4. It is easy for me to simplify integers with exponent using & 4.42 & Strongly Agree \\
exponential chips. & Strongly Agree \\
I enjoy simplifying expressions using exponential & 4.41 & Strongly Agree \\
6. I can learn best on hands-on experiences like using & 4.45 & Strongly Agree \\
7. I was able to visualize and answer the question easily & 4.44 &
\end{tabular}


8. I learned while working during the class.

9. I feel motivated in learning integral exponents using exponential chips.

10. I found exponential chips as a unique and creative way in learning integral exponents.

\section{OVERALL RATING**}

4.44

4.48

4.44

\author{
Strongly Agree \\ Strongly Agree \\ Strongly Agree \\ Very Useful
}

It shows that in both sections, all of the indicators got a mean rating of 4.1 and above which can be interpreted as strongly agree. Moreover, the perception of the grade 8 students in using exponential chips as manipulative in learning integral exponent got an overall rating of 4.44 which can be interpreted as very useful.

As revealed in the related literature McNeil (2009) emphasized that manipulative brings not only new perspective in the classroom but give additional resources to students to help them draw on practical, real-world knowledge and understanding. The result also supported in the study of Cockett (2015) that students were more engaged when manipulatives were used rather than when they were not used. He stated that the majority of students enjoy mathematics concepts. The perception of students is that mathematics manipulatives help them be more efficient in their work, better understand their work and receive greater enjoyment from the learning process.

Using manipulative as cognitive tools improved the teaching and learning process, and encourages student reflections on retaining the information. It has been claimed that the usage of a manipulative not only increases student achievement but also allows them to improve their conceptual understanding and problem-solving skills. The use of manipulative can also promote students to have a positive attitude towards mathematics. These manipulatives provide a block of concrete, hands-on experience, which can focus attention and overall increase motivation (Allen 2007). Thus, it can be concluded that the use of exponential chips as manipulative will help the students improve their performance in simplifying the expression with integral exponent.

Figure 3. Students working on exponential

chips

The figure shows the students working on exponential chips as manipulative used to represent the concept of learning integral exponent. The concrete manipulative creates an opportunity for students to represent the abstract concept of integral exponent which will help them to develop their conceptual understanding of the math concept. Manipulative brings a new perspective in the teaching-learning process in the classroom that cannot be done by pen and paper alone, McNeil (2009). It allows students to make use of their senses in learning as they explore both visually and tactilely. Through manipulative students gets to have hands-on experience which helps them to make connections to what they are learning and their hand movements as they interact with concrete objects. It has been claimed that the usage of manipulative not only increases student achievement but also allows them to improve their conceptual understand and problemsolving skills, Allen (2007).

Figure 4. Exponential chips sustain student's
The figure shows the student's interest in learning integral exponent while working on exponential chips as manipulative. They were more engaged in learning as they perceived exponential manipulative chips as a new and interesting way of learning the math concept. Thus, it helped them to have fun in the learning process which will, later on, result in better achievement. Cockett (2015) said that the majority of students enjoy the use of manipulatives and manipulatives improve the development of their mathematics concepts. The perception of students is that mathematics manipulatives help them to be more efficient in their work, better understand their work and receive greater enjoyment from the learning process. Carbonneau et al. (2013) added that by engaging students in learning through the use of manipulatives, educators can get students to become active players rather than passive bystanders of learning. And can promote students to have a positive attitude toward mathematics. These manipulatives provide a block of concrete, hands-on experience, which focus attention and overall increase motivation.

The difference between figure 3 and figure 4 is that in figure 3, students work on exponential chips to represent the mathematical concept of integral exponent which will help them to develop their conceptual understanding. While in figure 4 the students were engaged on exponential chips to sustain their interest while the facilitator helped them to achieve a conceptual understanding. In general, the students were given the opportunity on hands-on experience with exponential chips to both develop their conceptual understanding and sustain their interest throughout the discussion

\section{CONCLUSIONS}

Based on the results that we have gathered, the researchers, therefore, concluded that the performance level of the students got a satisfactory performance in post-test (simplifying expressions using exponential chips) than in pre-test (without using exponential chips), in which in pre-test it did not meet the expectation based on the DepEd rating system. The researchers also concluded that there is a significant difference between the performances of the grade 8 students in pre-test and post-test. And the post-test scores are significantly higher than the pre-test scores. This means that using exponential chips helped the students enhanced their performance in learning integral exponents. The researchers also concluded that the grade 8 students perceived exponential chips as very useful.

interest

This publication is licensed under Creative Commons Attribution CC BY.

http://dx.doi.org/10.29322/IJSRP.11.10.2021.p11826

WWW.ijsrp.org 


\section{REFERENCES}

[1] Acharya. B. (2017). Factors affecting in learning mathematics by mathematics learners, International and Journal of Elementary Education. Vol 6. No, 2. 2017, pp. 8-15 doi 10.116480/j.ijeedu 20170602.11

[2] Alghazo. Alsawaie, O. \& Al-Awidi. H, (2010) Enhancing counting of preschoolers through the use of computer technology and manipulatives./international Journal Of Learning, 17(9). 159-176

[3] Allen C., (2007). An action based research study on how using will increase students' achievement in Mathematics. Running head MANIPULATIVES Marygrove College.

[4] Amaya, M. M. Uttal, D. H.. O'Doherty. K. Dr, Liu. L. \&DeLoache. J. S. (2007) Two digit sub-traction: examining the link between concrete and abstract representations of knowledge. Cited in McNeil. N.. \&Jarvin. L.

[5] When theories don't add up: disentangling he manipulatives debate. Theory Into Practice, 46(4), 309-316

[6] Boggan, M., Harper, S. , \&Whitmjre, A. (2010). using manipulatives to teach elementary mathematics-Jouma! of Instructional Pedagog'es. Retrieved from http://www.aabri.com/manuscripts/10451 pdf

[7] Bouck, E. C.w Satsangi, Doughty, T. T. \& Courtney, W. T. (2014). Virtual and concrete manipulative: A comparison of approaches for solvtng mathematics problems for students with autism spectrum disorder. Journal of AutismDeve/opment Discord, 44, 180-193.

[8] Bryant, D. P. , Bryant, B, R. , Shin. M. \&Pfannenstiel, K. H. (2014). Learning disabilities: Mathematics characteristics and instructional exemplars. In S. Chinn (Ed.), The Routledge international handbook of dyscalculia and mathematical learning difficulties(pp. 243-256). London: Routledge.

[9] Carbonneau, K. J., Marley, S. C , Selig, J. P. (2013). A meta-analysis of the efficacy Of teaching mathematics with concrete manipulatives. Joumal of EducationalPsycho/ogy, 105(2), 380-400.

[10] Chinn, S. (2014). The Routledge international handbook of dyscalculia and mathematical learning difficulties, London: Routledge.

[11] Cockett A. (2015), Mathematical manipulatives: Creating an environment for understanding, efficiency, engagement and enjoyment Faculty engagement avondale community engagement.

[12] Cooper, T. E. (2012). Using virtual manipulatives with pre-service mathematics teachers to create representational models. International Joual For Technology In Mathematics Education, 19(3), 105-115.

[13] Domino, J. (2010). The effects in of gradesphysical manipulatives K-6: A on meta-analysis(Doctoralachievement in

[14] mathematics dissertation),Retrieved from ProQuest.(UMl 3423451)

[15] Florence, H. (2012). The effects of mathematics manipulatives. Retrieved

[16] September, 19, 2012 from http://www.ehow.com/info_8040301 effectsMathematics-manipulatives.html

[17] Fuson, K. C., \& Briars, D. J. (1990). Using a base-ten blocks learning/teaching

[18] approach for first-and second-grade place-value and multidigit addition and subtraction-Journa/ for Research in Mathematics Education, 21, 180- 206.

[19] Goracke, M. A. (2009) The role of manipulatives in the eighth grade mathematics classroom.Unpublished master's action research project, University of

[20] Heddens, J. W. (2007). Improving Researchmathematics teaching by using

[21] manipulatives. Retrieved October 2, 2007, from Kent State Universtiy Website:http://www.fed.cuhk.edu.hk/—fllee/mathfor/edumath/9706/13 hedd en.html.

[22] Hoke D. (2008), Effects on students performance of using hands on activities to teach seventh grade students measurement concepts. Orlando, Florida

[23] Jordan, L. , Miller, D. \& Mercer, C, (1999). The effects of concrete to semi concrete to abstract Instruction in the Acquisition and Retention of Fraction Concepts and Skills. Learning Disabilities: A Multidisciplinary Journal, 9(3), 115-122.

[24] Kentucky Center for Mathematics (2012). Retrieved from http://kentuckyMathematics.org/manipulatives.php.

[25] Kersaint, G. , Thompson, D. , Petkova, M, (2013). Teaching mathematics to english language learners. New York, NY: Routledge,

[26] Kosko, K. We, \& Wilkins, J. M. (2010). Mathematical communication and its relation to the frequency of manipulative use-International Electronic Journal Of MathematicsEducation, 5(2), 79-90.
[27] Maccini, P. , \& Hughes, C. A. (2000). Effects of a problem-solving strategy on the introductory algebra performance of secondary students with learning disabilities, Learning disabilities research \& practice, 15, 10-21.

[28] Marsh D. (2016), Using manipulatives to investigate ESOL students achievement and dispositions in algebra. Doctor of education in teacher leadership dissertations office of collaborative graduate programs.7-28,

[29] MathematicsAtube. (2012). What are manipulatives in mathematics? Retrieved September $\quad 12, \quad 2012$ from http://Mathematicswecamcom/articleMathematics-tips-I .html

[30] McNeill, DN., \&Jarvin, L. (2007), When theories don't add up: Disentangling the manipulativesdebate Theory into practice,46(4), 309-316.

[31] McNeil, N., \&Uttal, D. (2009), Rethinking the use of concrete materials in learning: Perspectives from development and education. Child development perspectives, 137-139.

[32] Morrison, M. (2011). Math Tracks: What pace in math is best for the middle school child? Montessori Life, 23(4), 26-35.

[33] Moyer, P.\&, Suh (2001). Are we having fun yet? How teachers use manipulatives to teach mathematics Fducational studies in mathematics, 47, 175-197. Retrieved August 22, 2012, from Wilson Web data base,

[34] National Council of Teachers of Mathematics. (2013). Retrieved April 2, 2014, fromhttp://nlvm.usu.edu/

[35] National Council of Teachers Of Mathematics (NCTM). (2000). Principles and standards for school mathematics. Reston, VA: National council of teachers of mathematics.

[36] National Governors Association Center for Best Practices. Council of Chief State

[37] School Officers (2010), Common core state standards mathematics. National Governors Association Center for Best Practices, Council of

[38] Chief State School Officers, Washington D.C.

[39] Ojose, B. (2008). Applying Piaget's theory of cognitive development to mathematics instruction. The mathematics educator. 18(1).

[40] J. (1977). Epistemology and psychology of functions. Dordrecht, Netherlands: D. Reidel Publishing Company

[41] Peterson, S., Mercer, C, D.\& O'Shea, L. (1988). Teaching learning disabled students place value using the concrete to abstract sequence. Learning disabilitiesresearch, 4(1), 52-56.

[42] Piaget, J. (1965). The child's conception of number. New York: W, W Norton \& Company.

[43] Ramazan A. (201 0), Eight grader's capabilities in exponent: Making mental comparison.practice and theory in systems of education. Aksaray University, Aksaray, Turkey Volume 5.39

[44] Reeves R. A. \& Gray, S. (2014). Number difficulties in young children, In S. Chinn (Ed.), The Routledge international handbook of dyscalculia and mathematical learningdifficulties(pp, 44-59). London: Routledge.

[45] Rosen, D., \&Hoffman, J. (2009).Integrating concrete and virtual manipulatives in early childhood mathematics. Young children, 64(3), 26-33.

[46] Ross, A-s \&Willson, V, (2012). The effects of representations, constructivist approaches, and engagement on middle school students' algebraic procedure and conceptual understanding. School Science and Mathematics, 112(2), 117-128. https://doi.org/lffll 11/119498594.2011.00125.x

[47] Rubin R., Marcelino J.. \&Mortel R. et.al.(2014). Activity-based teaching of integer concepts and its operations Presented at the DLSU research congress.

[48] \$enay,

S.C.(2002):Uslüvekdklüsayllannöåretimindeöérencilerinyaptlklanmaster $\quad t$ Unpublished Selvuk University, Konya.

hatalarveyamlgllarlüzerinebirara*ttrma

[49] Shaw, J. M. (2002). Manipulatives enhance the learning of mathematics. RetrievedSeptember12,2012fromhttp ://www.eduplace.com/state/author/shaw.pdf,

[50] Stein, M. K., \&Bovalino, J. W. (2001). Manipulatives: One piece of the puzzle. mathematicsteachingin the middle 356-359.

[51] Stellingwerf, B. P., \&Lieshout, E. C. D. M. (1999). Manipulatives and number sentences in computer aided arithmetic word problem solving, Instructional Science, 27(6), 459-476,

[52] Swan, P.. \& Marshall, L. (2010).Revisiting mathematics manipulative materials.Australian primary mathematics classroom, 15(2), 13-19. 
[53] Tall D.O (2003) Using theoretical computational conflicts to enrich the concepts image of derivative. Research in mathematics education,vol 5 , pp. 63-78.

[54] Uribe-Florez, L. J.. \& Wilkins, J. M. (2010).Elementary school teachers' manipulative use.School science and mathematics, 110(7).

[55] Uttal, D. H, (2003). On the relation between play and symbolic thought: The case of Mathematics manipulatives.Contemporary perspectives on play in early childhood education, 1(6), 97-114.

[56] Uttal D. , Scudder K. , \&Deloache J.(1997). Manipulatives as symbols: A new perspective on the use of concrete objects to teach mathematics. Journal of Applied Developmental Psychology 18,37-54, ISSN 0193-3973.

[57] Wang, A. (2010). Optimizng early mathematics experience for children from low-income Families: A study on opportunity to learn Mathematics, Early Childhood Education, 37(J), 295-302.

[58] Xie, L. , Antle, A. N. , \&Motamedi, N. (2008). Are tangibles more fun? Comparing children's enjoyment and engagement using physical, graphical and tangible user interfaces. doi:10,1145/1347390.1347433

[59] Yuan, Y. Y., Lee, C. Y., \& Wang, C. H. (2010).A comparison study of polyominoes explorations in a physical and virtual manipulative environment Aournal Of Computer Assisted Learning, 26(4), 307-316.

\section{AUTHORS}

First Author - Grace P. Guliman

Second Author - Emybel M. Alegre,PhD

\section{SUMMARY}

The main purpose of the study was to determine the performance level of the respondents in learning integral exponents with and without the aid of exponential manipulative chips, and if there is a significant difference between the performance level of the respondents in the pre-test and post-test. It also seeks to answer what is the respondents' perception in using exponential manipulative chips in learning integral exponent. The researchers hypothesized that there is no significant difference between the performance level of the respondents in the pre-test and post-test in learning integral exponent.

The descriptive method was used in this study in order to achieve the objectives 